OPEN ACCESS

Edited by:

Karam B. Singh,

Commonwealth Scientific and Industrial Research Organisation

(CSIRO), Australia

Reviewed by:

Dongying Gao,

University of Georgia,

United States

Ken Chalmers,

University of Adelaide, Australia

*Correspondence:

Bruno Studer

Bruno.studer@usys.ethz.ch

tThese authors share senior authorship

Specialty section:

This article was submitted to Legumes for Global Food Security,

a section of the journal

Frontiers in Plant Science

Received: 14 May 2019

Accepted: 15 August 2019 Published: 12 September 2019

Citation: Nay MM, Mukankusi CM, Studer B and Raatz B (2019) Haplotypes at the Phg-2 Locus Are Determining Pathotype-Specificity of Angular Leaf Spot Resistance in Common Bean.

Front. Plant Sci. 10:1126. doi: 10.3389/fpls.2019.01126

\section{Haplotypes at the Phg-2 Locus Are Determining Pathotype-Specificity of Angular Leaf Spot Resistance in Common Bean}

\author{
Michelle M. Nay ${ }^{1}$, Clare M. Mukankusi ${ }^{2}$, Bruno Studer ${ }^{1 \star \dagger}$ and Bodo Raatz ${ }^{3+}$ \\ ${ }^{1}$ Molecular Plant Breeding, Institute of Agricultural Sciences, ETH Zurich, Zurich, Switzerland, ${ }^{2}$ Bean Program, International \\ Center for Tropical Agriculture (CIAT), Kampala, Uganda, ${ }^{3}$ Bean Program, International Center for Tropical Agriculture (CIAT), \\ Cali, Colombia
}

Angular leaf spot (ALS) is one of the most devastating diseases of common bean (Phaseolus vulgaris L.) and causes serious yield losses worldwide. ALS resistance is reportedly pathotype-specific, but little is known about the efficacy of resistance loci against different pathotypes. Here, we report on ALS resistance evaluations of 316 bean lines under greenhouse and field conditions at multiple sites in Colombia and Uganda. Surprisingly, genome-wide association studies revealed only two of the five previously described resistance loci to be significantly associated with ALS resistance. Phg-2 on chromosome eight was crucial for ALS resistance in all trials, while the resistance locus Phg-4 on chromosome 4 was effective against one particular pathotype. Further dissection of Phg-2 uncovered an unprecedented diversity of functional haplotypes for a resistance locus in common bean. DNA sequence-based clustering identified eleven haplotype groups at Phg-2. One haplotype group conferred broad-spectrum ALS resistance, six showed pathotype-specific effects, and the remaining seven did not exhibit clear resistance patterns. Our research highlights the importance of ALS pathotype-specificity for durable resistance management strategies in common bean. Molecular markers co-segregating with resistance loci and haplotypes will increase breeding efficiency for ALS resistance and allow to react faster to future changes in pathogen pressure and composition.

\begin{abstract}
Keywords: food security, plant breeding, plant pathology, genome-wide association studies (GWAS), pathotypespecificity, common bean (Phaseolus vulgaris L.), angular leaf spot (ALS), Pseudocercospora griseola
\end{abstract}

\section{INTRODUCTION}

Plant diseases can cause substantial loss of crop yields with detrimental effects on food security (Oerke, 2006; Savary et al., 2012). In Latin America and Africa, for example, common bean (Phaseolus vulgaris $\mathrm{L}$.) is one of the most important crops and particularly valued for its protein and micronutrient content. However, common bean production is frequently reduced by pathogen attacks with angular leaf spot (ALS), caused by Pseudocercospora griseola (Sacc.) Crous and Braun (Crous et al., 2006), being one of the most devastating common bean diseases in the tropics and subtropics. ALS has been reported to cause yield losses of up to 80\% (Schwartz et al., 1981; Correa-Victoria et al., 1989; 
Saettler, 1991; Wortmann et al., 1998; Stenglein et al., 2003; Sartorato, 2004). In the tropics and subtropics, common beans are mostly cultivated by smallholder farmers with limited possibilities to protect their crops from diseases or adverse climatic conditions and, therefore, depend on resistant common bean varieties to maintain stable yields (Schwartz and Pastor-Corrales, 1989).

Common bean germplasm can be divided into two gene pools, the Andean and the Mesoamerican gene pool (Gepts and Debouck, 1991; Mamidi et al., 2013). The latter, genetically more diverse Mesoamerican gene pool has been reported to contain more and stronger ALS resistance sources (Nay et al., 2019). Breeding for ALS resistance is challenged by the high genetic diversity of the pathogen and the recurrent appearance of new P. griseola pathotypes (Pastor-Corrales et al., 1998; Busogoro et al., 1999; Mahuku et al., 2002a). To categorize pathotypes, they are tested for their ability to infect six Andean and six Mesoamerican common bean lines with distinct resistance patterns (also referred to as differentials), in order to determine their race (Pastor-Corrales and Jara, 1995; Nay et al., 2019). The ALS pathogen co-evolved within the two common bean gene pools into Andean races, only causing disease on Andean beans, and Mesoamerican races, showing a higher specificity for Mesoamerican beans but also attacking beans of the Andean gene pool (Gepts and Debouck, 1991; Guzmán et al., 1995; PastorCorrales et al., 1998; Mamidi et al., 2013; Schmutz et al., 2014). Resistance in common bean has been reported to be pathotypespecific with large differences of the effectiveness in different locations and continents (Pastor-Corrales and Jara, 1995; PastorCorrales et al., 1998; Mahuku et al., 2002b; Silva et al., 2008).

Previous ALS resistance studies defined five repeatedly characterized resistance loci, in addition to several minor resistance sources (reviewed in Nay et al., 2019): Phg-1 was found in the line AND 277, closely linked to the anthracnosis resistance locus $\mathrm{Co}-1^{4}$ at the lower end of chromosome (Chr) 1 (Carvalho et al., 1998; Gonçalves-Vidigal et al., 2011). Phg-2 was found on Chr 8 in the Mesoamerican lines Mexico 54, with potential resistant alleles in Cornell 49-424, BAT 332, MAR 2, G10474, and G10909 (Sartorato et al., 1999; Ferreira et al., 2000; Nietsche et al., 2000; Caixeta et al., 2003; Mahuku et al., 2004; Mahuku et al., 2011). The Phg-3 locus was found in Ouro Negro on the lower arm of Chr 4 and Phg-4 in G5686 on the upper arm (Corrêa et al., 2001; Mahuku et al., 2009; Keller et al., 2015). Phg-5 was found in the lines CAL 143 and G5686 on Chr 10 (Oblessuc et al., 2012; Keller et al., 2015). Besides these well-characterized major resistance loci, indications for quantitative resistance were reported (Teixeira et al., 2005; Oblessuc et al., 2012; Keller et al., 2015; Bassi et al., 2017).

All the above-mentioned studies were conducted in bi-parental mapping populations, limiting the allelic diversity in the population to the two parental alleles. The establishment of such mapping populations is laborious, and the resistance loci found in such experiments may only be effective in the original background due to epistatic effects (Holland, 2004; Kumar et al., 2014). In addition, bi-parental mapping studies were often tested for ALS resistance with a single pathotype or at a single field location, even though the pathotype-specific resistance reaction of $P$. griseola is well described (Pastor-Corrales et al.,
1998; Corrêa et al., 2001; Mahuku et al., 2002b; Mahuku et al., 2009; Gonçalves-Vidigal et al., 2011; Mahuku et al., 2011; Oblessuc et al., 2012; Ddamulira et al., 2014; Bassi et al., 2017). Hence, little is known about the range of effectiveness and the interaction of different ALS resistance loci in common bean in different environments with possibly different pathotypes. Furthermore, all previous mapping studies were conducted with Latin American pathotypes, and it is unknown whether the same resistance loci are effective against pathotypes from Africa.

Genome-wide association studies (GWAS) in panels specifically assembled to contain breeding germplasm with phenotypic variability for the trait of interest can overcome the above-mentioned limitations of bi-parental mapping populations. This type of analysis became possible through technological advancements, particularly in next generation sequencing, which allows to genotype hundreds of individuals at a sufficiently high marker density to cover the linkage disequilibrium blocks and to find trait-specific single nucleotide polymorphisms (SNPs) for breeding. By testing a diversity panel with different pathotypes, GWAS enables the identification of pathotype-specific resistance loci as has been recently demonstrated for anthracnose (Zuiderveen et al., 2016).

The main objective of this study was to gain a broader understanding of ALS resistance sources, the resistance loci they contain, and their effectiveness against different pathotypes on two continents. Specifically, we aimed at i) assembling a panel consisting of the currently available ALS resistance sources, ii) evaluating its resistance against multiple ALS pathotypes under greenhouse and field conditions, and iii) identifying pathotype- and field location-specific resistance loci and haplotypes through genotyping by sequencing (GBS) and GWAS.

\section{MATERIALS AND METHODS}

\section{Plant Material}

An association mapping panel of 316 common bean lines, named extended BALSIT (extBALSIT), was used for ALS resistance evaluations and GWAS. ExtBALSIT included the Bean ALS International Trial (BALSIT) panel consisting of 55 lines, complemented with previously characterized resistance sources (Carvalho et al., 1998; Sartorato et al., 1999; Ferreira et al., 2000; Nietsche et al., 2000; Corrêa et al., 2001; Caixeta et al., 2003; Mahuku et al., 2003; Mahuku et al., 2004; Mahuku et al., 2009; Gonçalves-Vidigal et al., 2011; Mahuku et al., 2011; Oblessuc et al., 2012; Keller et al., 2015), CIAT breeding material with phenotypic variability for ALS response and susceptible checks. The panel included 124 large-seeded Andean beans, 129 small-seeded Mesoamerican, and 63 lines from inter-gene pool crosses. The 316 common bean lines of the extBALSIT panel were multiplied, out of which 264 lines received phytosanitary certificates and were shipped from Colombia to Uganda for ALS-resistance evaluation.

\section{Evaluation of Angular Leaf Spot Disease Resistance}

The extBALSIT panel was evaluated for ALS resistance in the greenhouse with single-spore $P$. griseola isolates and in the field 
with mixes of isolates. Highly pathogenic Mesoamerican and Andean races were chosen for the greenhouse experiments. Isolates belonging to races 63-63, 63-47, 30-0, and 13-63 were used in Colombia and race 61-63 in Uganda. In the field, inoculations were conducted with pathogen isolates previously collected at the respective field sites in Colombia and different districts in Uganda (Supplementary Table 1). Disease severity was evaluated with the CIAT standard scale ranging from 1 (no disease symptoms) to 9 (very severe disease symptoms and defoliation) (van Schoonhoven and Pastor-Corrales, 1987).

Greenhouse experiments were conducted at CIAT headquarters in Colombia (Cali) and at CIAT in Uganda (Kawanda). Three and five seeds of each common bean line were planted per pot under well-watered conditions in Colombia and Uganda, respectively. In Colombia, primary leaves were treated with Elosal (Bayer Crop Science, Monheim am Rhein, Germany) eight days after sowing, to prevent powdery mildew infections, and urea was added before inoculations. For each pathotype, two replicates in time were screened with each replicate containing one pot per line of the extBALSIT panel. Pathogen isolates were grown in $\mathrm{V}_{8}$ medium (Castellanos et al., 2016) for 8-20 days before inoculation, depending on growth rate of the isolate. Inoculum was prepared according to the CIAT manual (Castellanos et al., 2016) and spray-inoculated on trifoliate leaves of 17-day-old plants in Colombia, and 21-day-old plants in Uganda. After inoculation, plants were transferred to a humidity chamber for four days in Colombia, while in Uganda, they were covered with a plastic bag for three days to increase humidity. Ten days after inoculation, plant disease scores were evaluated four times within a week, usually on days 10,12,14, and 17. Because of the slow disease progression in Uganda, an additional evaluation was conducted 21 days after inoculation.

Field experiments were conducted during the rainy season in October 2016 and 2017 in Darien (N3 53'31" W76 31'0," 1,491 m a.s.l.) and Quilichao (N304'22" W76 29'55," $991 \mathrm{~m}$ a.s.l.), Colombia, and in May 2018 in Kawanda (N0²4'11" E32 $31^{\circ}$ '54," $1,178 \mathrm{~m}$ a.s.1.), Uganda. Common bean lines were evaluated as single rows in Colombia and in a randomized complete block design with two replicates in Uganda. The rows measured 2.5-3 $\mathrm{m}$ in Colombia and $5 \mathrm{~m}$ in Uganda, the distance between rows measured $0.6 \mathrm{~m}$, and seeds were sown with a density of 10 seeds $/ \mathrm{m}$. Susceptible and resistant checks were added every eight rows, and a border of susceptible checks was planted to favor spread of the disease. Plants were inoculated three times in a weekly interval using a backpack sprayer, starting approximately 20 days after planting when the third trifoliate leaf of most plants was fully extended (stage V4, according to van Schoonhoven and Pastor-Corrales (1987)). ALS symptoms on leaves were also evaluated three times in a weekly interval and started at the appearance of the first disease symptoms approximately 40 days after inoculation. Pods were evaluated at the mid-pod fill stage, approximately 3 weeks after the last foliar evaluation (exact dates are given in Supplementary Table 2). Phenotypic data of the extBALSIT panel is available on dataverse.org (https://doi. org/10.7910/DVN/U2BAWN).

Inoculum was prepared according to Castellanos et al. (2016), as a mixture of five, six, and five single-spore pathogen isolates in
Darien, Quilichao, and Kawanda, respectively (Supplementary Table 1). The isolates in Uganda did not sporulate well and a precise adjustment of the spore concentration was not possible. Therefore, fungal mycelium of 70 petri dishes was scraped off and diluted in water for the first inoculation and 35 petri dishes for the subsequent inoculations.

\section{DNA Extraction and Genotyping}

For genotyping, three emerging trifoliate leaves were sampled and used for DNA extraction following a urea-phenolchloroform-isoamylalcohol protocol reported by Chen et al. (1992). DNA quality was checked by agarose gel electrophoresis and quantified by absorption of fluoresce using PicoGreen to stain double stranded DNA (Molecular Probes Inc., Eugene OR, USA). The common bean lines of the extBALSIT panel were subjected to GBS according to Elshire et al. (2011) with the following modifications: adaptor concentrations were $6 \mathrm{ng} / \mu \mathrm{l}$, digestion per reaction was conducted with $0.5 \mu$ restriction enzyme ApeKI (50 U/ $\mu$ l, New England Biolabs [NEB], Ipswich MA, USA), ligation with $0.5 \mu$ ligase $(20 \mathrm{U} / \mu \mathrm{l}$, Promega, Madison WI, USA) and $3 \mu$ l buffer per sample, filled up with $\mathrm{ddH}_{2} \mathrm{O}$ to reach the target reaction volume. After adapter ligation, the 96 samples were pooled and cleaned with a PCR Clean-Up System (Promega), according to the manufacturer's protocol. For each pool, PCR was conducted in duplicate and merged afterwards. Each PCR reaction with a total volume of $50 \mu \mathrm{l}$ contained $1 \mathrm{x}$ buffer (10 mM Tris- $\mathrm{HCl} \mathrm{pH} 8.8,50 \mathrm{mM} \mathrm{KCl,} \mathrm{0.8 \%} \mathrm{[v/v]} \mathrm{Nonidet}$ P40 [Fermentas, Waltham MA, USA]), $2 \mathrm{mM} \mathrm{MgCl}_{2}, 0.1 \%$ bovine serum albumin, $1 \%$ polyvinylpyrrolidone, $0.016 \mu \mathrm{M}$ of each primer, $0.4 \mathrm{mM}$ dNTP, $0.3 \mu \mathrm{TAQ}$ polymerase (Sigma-Aldrich, St. Louis MN, USA), and $2 \mu$ DNA template. Primers used for amplification were the following: forward PCR_Primer1_Short: AATGATACGGCGACCACCGAGATCTACACTCTTTCCC TACACGACGC and reverse PCR_Primer2.1.i7: AAGCAG AAGACGGCATACGAGATGTCGATTGTGACTGGA GTTCAGATGTGTG. Each library containing 96 individually barcoded genotypes was sequenced by 150 bp single end sequencing on a single lane of the Illumina HiSeq Instrument (Illumina, San Diego CA, USA) at Hudson Alpha sequencing facility (Huntsville AL, USA). For SNP calling, the NGSEP pipeline (Perea et al., 2016) was used with the following quality criteria: a minimum quality score of Q40, scores in at least 220 of the 316 common bean lines, a minor allele frequency exceeding $5 \%$, and a heterozygosity rate below $6 \%$. Subsequently, heterozygous data points were removed. Genomic positions of SNPs and candidate genes were inferred according to the v2.1 of the $P$. vulgaris reference genome (available at https://phytozome. jgi.doe.gov, accessed 11. Nov. 2018). Genotypic information of the extBALSIT panel is available on dataverse.org (https://doi. org/10.7910/DVN/U2BAWN).

\section{Genome-Wide Association Studies}

Genotype to phenotype associations were identified with TASSEL 5 (Bradbury et al., 2007). For greenhouse and field trials, mean ALS scores from the last evaluation of the trial were used. A mixed linear model was implemented using principal component analysis (PCA) with the first two principal components to 
correct for population structure and the K matrix to correct for kinship (Bradbury et al., 2007). Within TASSEL, the kinship was calculated using the centered identity-by-state (IBS) method, P3D was implemented for variance component analysis, and no compression was used (Zhang et al., 2010; Endelman and Jannink, 2012). The significance threshold was adjusted with the Bonferroni correction. TASSEL output and phenotypic data were analyzed and plotted using RStudio (version 3.4.4) with the packages qqman, ggplot2, reshape2, and psych (R Core Team, 2008).

\section{Haplotype Analysis at the Phg-2 Locus}

In order to group the haplotypes at the Phg-2 locus on $\mathrm{Chr} 8$, SNPs located in the interval of significant associations (i.e., from position $61,150,549-62,934,224$ bp in the reference genome sequence) were clustered using a hierarchical clustering method implemented in $\mathrm{R}$. The 276 common bean lines with less than 50\% missing SNP data in the interval were retained for analysis. The genotype matrix was translated to numeric values, Euclidian distance between the common bean lines calculated and hierarchical clustering according to the Ward.D2 method was performed (Ward, 1963; Murtagh and Legendre, 2014). The resulting dendrogram was cut to group the haplotypes into eleven groups. The haplotype groups were named Andean or Mesoamerican, according to the gene pool of the lines from which the haplotypes originated. To evaluate the effect of the haplotypes, the disease scores of each haplotype for each experiment were plotted in $\mathrm{R}$.

\section{RESULTS}

\section{Angular Leaf Spot Resistance Is Highly Location- and Pathotype-Specific}

Evaluation of the extBALSIT panel for ALS resistance revealed trial-specific frequency distributions of ALS scores (Figure 1, Supplementary Figure 1). Differences were observed between continents, locations, greenhouse and field experiments, and different pathotypes. For most trials, a continuous distribution of disease scores was found, only in the greenhouse experiment with pathotype COL 30-0, the histogram clearly differentiated resistant and susceptible lines, indicating major gene resistance. Twenty-seven lines were found resistant (ALS score $\leq 3$ on a 1 to 9 scale) in all 6 trials conducted in Colombia, 43 were resistant in the 2 trials conducted in Uganda, and 2 (AAB 8-2, G6727) were resistant in all experiments. The differences between the continents were also notable: of the 46 most resistant lines in Colombia (average ALS leaf score over all experiments $\leq 3$ ), only 15 had an average score of $\leq 3$ against the Ugandan pathotypes tested.

Out of the 55 pairwise correlations between phenotypic data of the trials, 43 (78\%) were significant (Pearson correlation, $P<$ 0.05 ), ranging from 0.12 to 0.73 (Supplementary Figure 2). Highest correlations were observed between the replicates of the field experiment in Kawanda, Uganda, and the comparison of field data between years in Darien and Quilichao, Colombia (Supplementary Table 3).

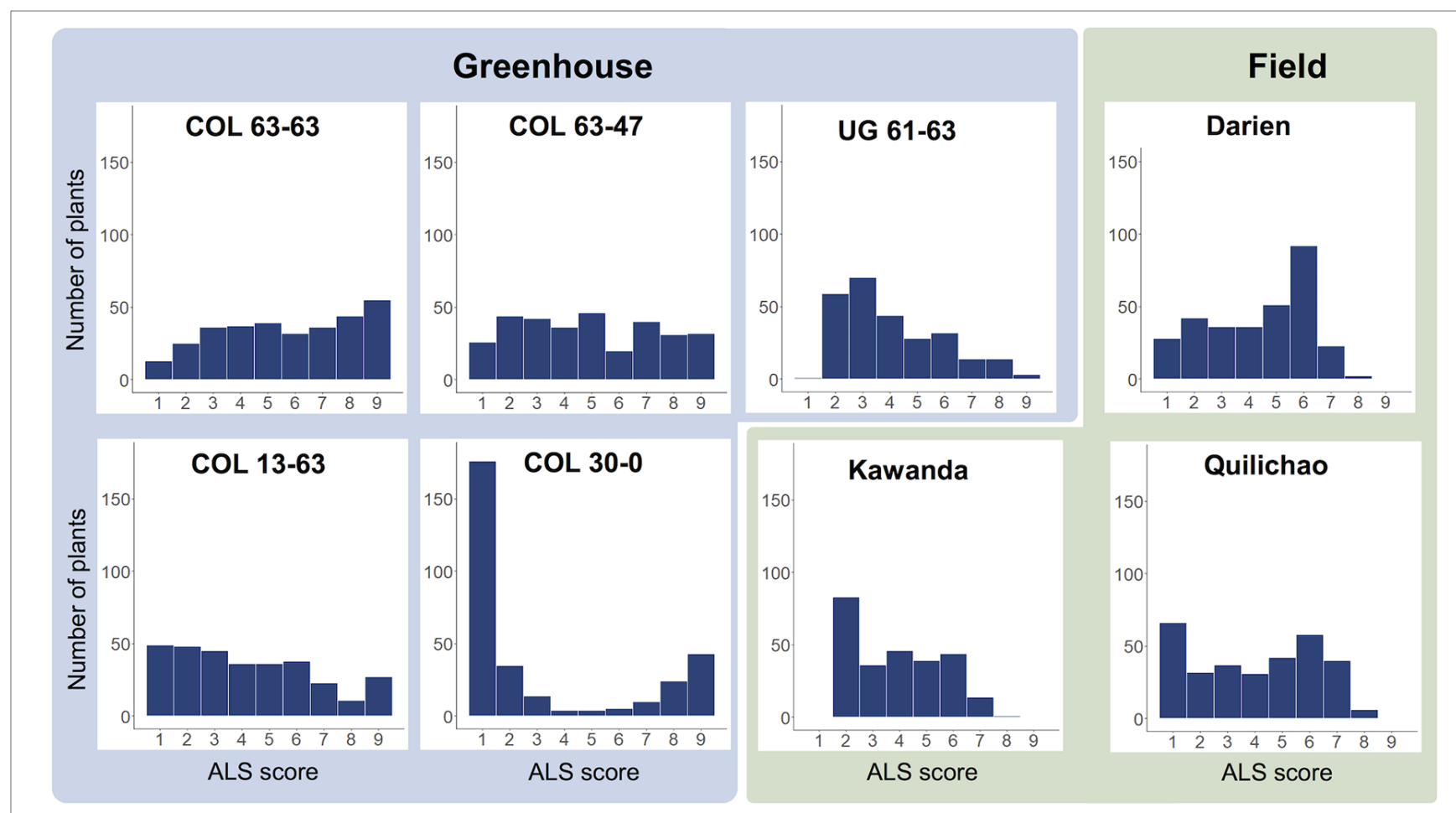

FIGURE 1 | Frequency distributions of disease scores for angular leaf spot (ALS), evaluated in greenhouse (blue) and field trials (green) using the extBALSIT panel containing 316 common bean lines. ALS was scored on a scale from 1 to 9 , where 1 is resistant and 9 is highly susceptible. The greenhouse trials were conducted with five different pathotypes, determined by their origin (COL and UG) and race (63-63, 63-47, 61-63, 13-63, and 30-0). Field trials in Colombia (Darien and Quilichao) and Uganda (Kawanda) were inoculated with mixtures of pathotypes previously collected at the corresponding sites. For Darien and Quilichao, the average ALS score from both evaluation years is shown. 


\section{Genome-Wide Association Studies Confirm ALS Resistance Loci on Chromosomes 4 and 8 of Common Bean}

Genotyping by sequencing of the extBALSIT panel revealed 22,765 high-quality SNPs distributed over the eleven choromosomes of common bean (Supplementary Figure 3). The population structure of the extBALSIT panel was analyzed with PCA, on the basis of the SNP marker data (Supplementary Figure 4). The first PC explained $45 \%$ of the genotypic variance and clearly distinguished Andean and Mesoamerican lines, with lines that originated from inter-gene pool crosses clustering between them. The second PC explained $4 \%$ and distinguished lines that originated from a cross between G10474 and G5687 (referred to as RAI lines) from the remaining inter-gene pool crosses. The second PC further separated the Mesoamerican lines G10613, G10474, G10909, G18970, G855, Mexico 54, G1805, Flor de Mayo, MAR 2, and G5653. The first six of these accessions were collected in Guatemala or neighboring Oaxaca and likely belong to the highly ALS-resistant subpopulation previously characterized in Guatemala (Beebe et al., 2000; Mahuku et al., 2003; CIAT Genebank, 2018; Lobaton et al., 2018).

Genotype to phenotype associations were investigated by GWAS. In all but one trial, foliar ALS resistance was significantly associated with a region on Chr 8 (Figure 2). For the field trial in Uganda (Kawanda), a peak is clearly visible in the Manhattan plot, but it is not passing the stringent Bonferroni threshold. Manhattan plots indicate the same resistance locus on Chr 8 to be effective in Colombia as well as in Uganda. The interval where significant associations were found in this study on Chr 8 coincides with the genomic region where molecular markers linked to the Phg-2 resistance locus in the common bean line Mexico 54 and G10474 were found (Sartorato et al., 1999; Sartorato et al., 2000; Gil et al., 2019), hence, it will be referred to as the Phg-2 locus. GWAS analyses of ALS symptoms on pods at one of the field locations in Colombia (Darien) resulted in the same resistance locus on Chr 8. Pod evaluations at the other field locations in Colombia (Quilichao) and Uganda (Kawanda), where phenotypic variability was low, did not result in significant associations to markers in the GWAS analysis (Supplementary Figure 5). In addition to the predominant signal on $\mathrm{Chr} 8$, another resistance locus on $\mathrm{Chr}$ 4 was effective against the pathotype COL $30-0$. This resistance locus coincided with the mapping interval of the Phg-4 locus (Keller et al., 2015).

Over all experiments, significantly associated SNPs were found in the interval spanning 61,150,549-62,934,224 bp (total length of 1,784 kbp) on Chr 8 and 46,703,147-46,934,061 bp (total length of $231 \mathrm{kbp}$ ) on $\mathrm{Chr} 4$. In the interval on Chr 8, 265 annotated genes were identified, of which two (Phvul.008G284500, Phvul.008G285300) were NB-ARC domain-containing disease resistance genes (PF00931), another 2 (Phvul.008G267600, Phvul.008G267700) were of the TIRNBS-LRR class (PF13676, PF01582), and 20 were containing leucine-rich repeats. On Chr 4, 28 annotated genes were found in the interval, but no putative resistance genes were among them. Significant SNPs on Chr 8 explained highest percentages of phenotypic variance, between $8.6-31.4 \%$, in line with the very dominant role of this resistance locus seen in these experiments. Markers associated with the resistance locus on Chr 4 explained $9.3-11.4 \%$ of the variance.

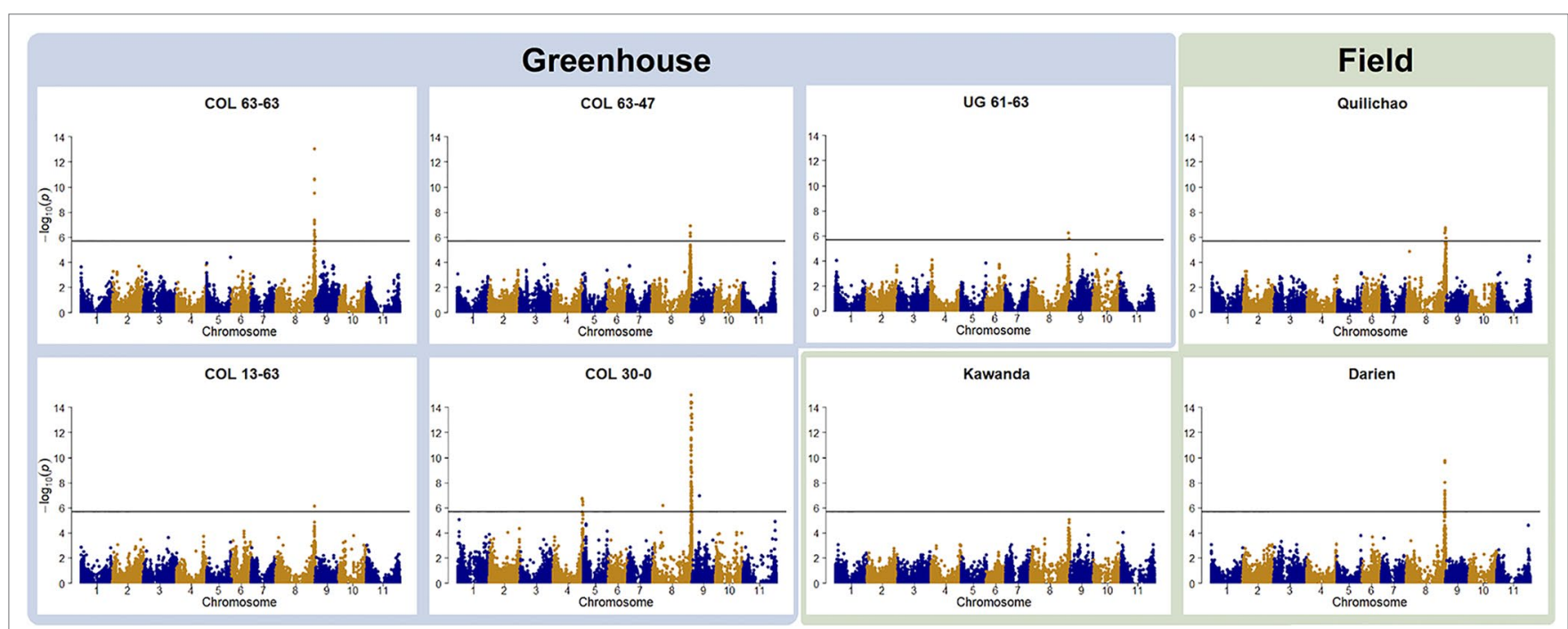

FIGURE 2 | Manhattan plots of the genome-wide association studies (GWAS) for angular leaf spot (ALS) resistance in the extBALSIT panel. The greenhouse trials were conducted with five different pathotypes, determined by their origin (COL and UG) and race (63-63, 63-47, 61-63, 13-63, and 30-0). Field trials in Colombia (Darien and Quilichao) and Uganda (Kawanda) were inoculated with mixtures of pathotypes, previously collected at the corresponding sites. On the x-axis, the genomic position of the markers is given. On the $y$-axis, the negative logarithm to the base 10 of the $P$-value, representing the significance value, is given. In order to correct for multiple testing, the significance threshold was adjusted through the Bonferroni method, and the new significance threshold is depicted by the black horizontal line. 


\section{Haplotypes of the Resistance Locus on Chromosome 8 Explain ALS Pathotype-Specificity}

Haplotypes at the Phg-2 locus, identified through cluster analysis of the SNP data in the Phg-2 region, were categorized into eleven groups (M1 to M5, M/A, A1 to A5, Figure 3) and associated with trial-specific ALS resistance scores (Figure 4, Supplementary Figure 6). The haplotype groups M1 to M5, originating from the Mesoamerican gene pool, were resistant against the pathotype COL $30-0$, as indicated by its race code. Common bean lines from the Mesoamerican haplotype group M1 were resistant in nearly all experiments but showed intermediate resistance in the trial with the
Ugandan pathotype UG 61-63. Lines from the haplotype groups M2 and M3 were resistant against COL 14-63, UG 61-63, and the pathotypes present in the field in Quilichao and Kawanda but were susceptible to pathotypes present in the field in Darien and the most aggressive race COL 63-63. Lines from the haplotype group M4 showed increased resistance against UG 61-63 and COL 13-63 but were less effective compared to M2 and M3. Lines from the haplotype group M5 were largely resistant against pathogen races in Darien and Kawanda, but no clear trend was observed in the other experiments.

Andean haplotype groups at the Phg-2 locus were mostly associated with susceptibility to ALS. A1 and A2 only displayed effective resistance against COL $30-0$, and A1 and A3 appeared

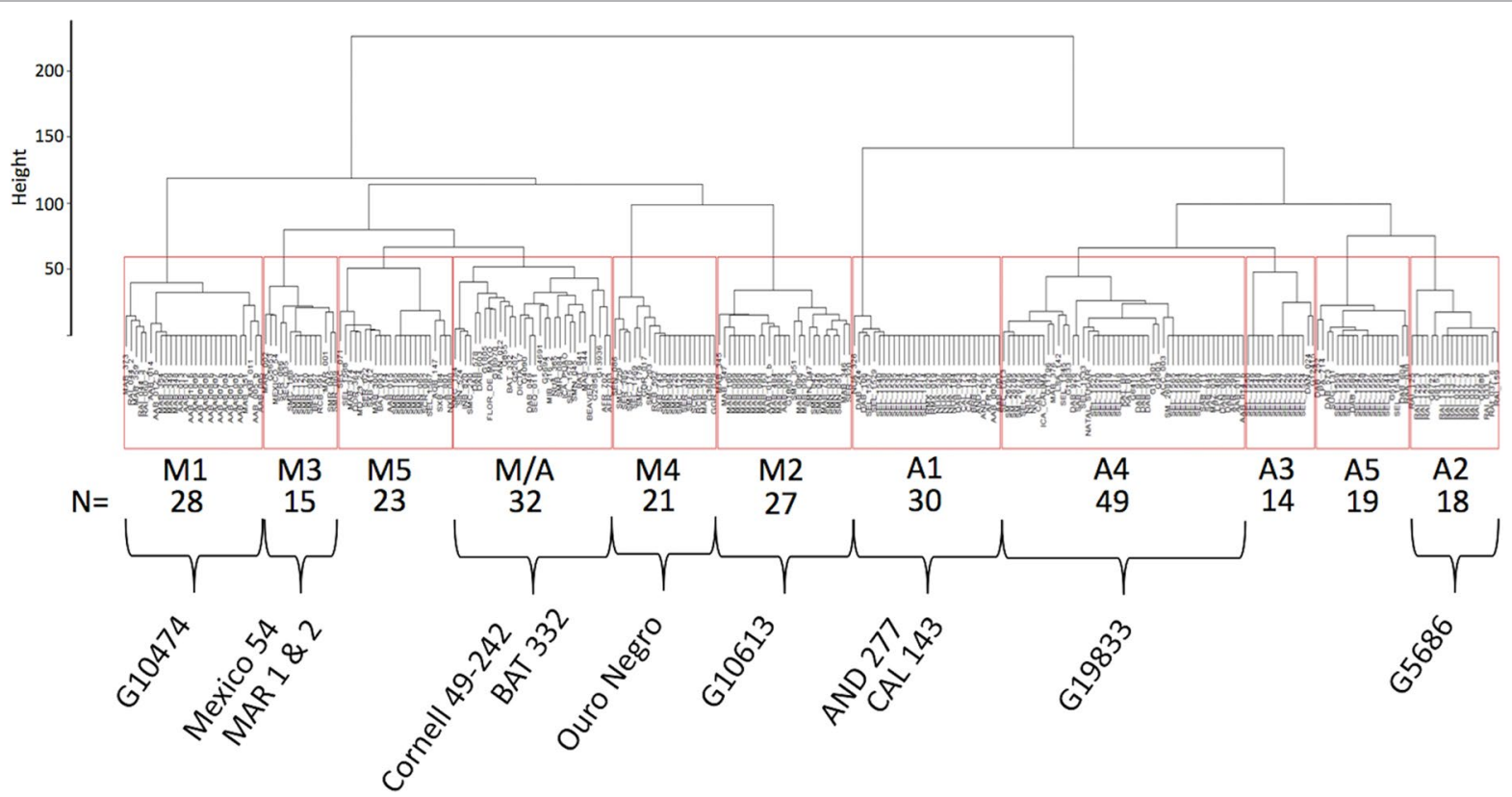

FIGURE 3 | Dendrogram of hierarchical clustering at the Phg-2 locus. The common bean lines of the extBALSIT panel were clustered according to similarity of their SNP data in the 61.15-62.93 Mbp interval on Chr 8 and divided into eleven haplotype groups. Haplotype groups were named according to the gene pool of the lines ( $\mathrm{M}$, Mesoamerican; $\mathrm{A}, \mathrm{Andean}$; and $\mathrm{M} / \mathrm{A}=$ mixed) and numbered. Below the haplotype names, the number of common bean lines in each haplotype group is given and well known ALS resistant common bean lines as well as the reference genome line (G19833) contained in the haplotype groups are indicated. On the $y$-axis, the Euclidian distance between clusters is shown.

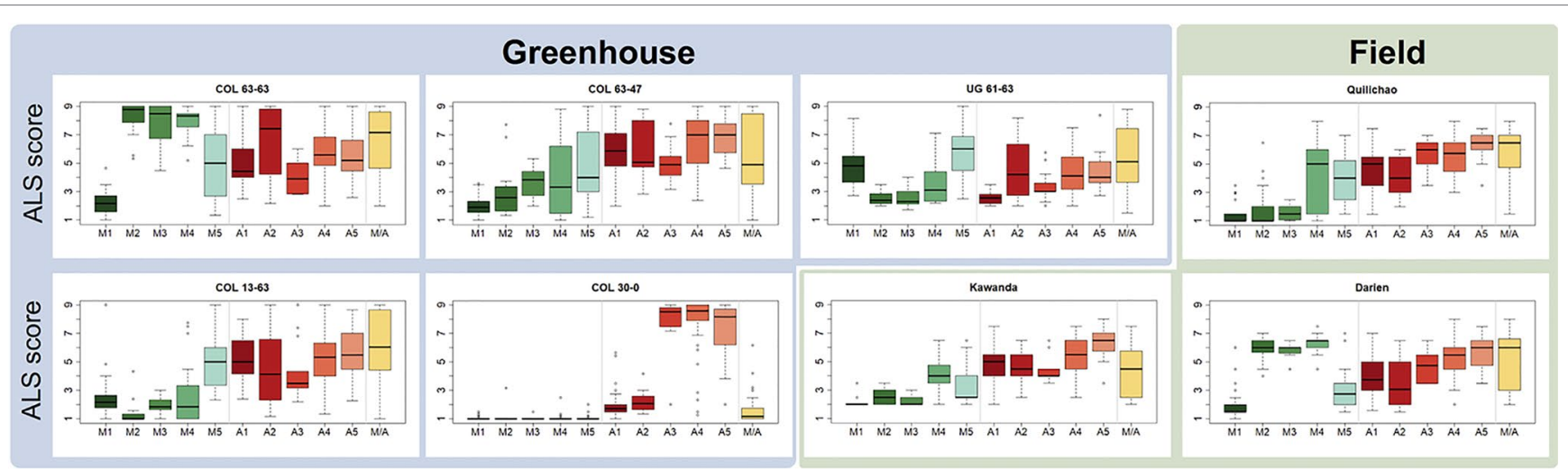

FIGURE 4 | Haplotype groups at the Phg-2 locus and their ALS response, as evaluated in greenhouse and field trials using the extBALSIT panel. For each trial, the ALS response, scored on a scale from 1 (resistant) to 9 (susceptible), is shown for each of the eleven haplotype groups. 
resistant against UG 61-63. Lines from the haplotype groups A4, A5, and $\mathrm{M} / \mathrm{A}$ were mostly susceptible in all experiments. The haplotypes at the Phg-2 locus were able to explain a much larger fraction of the total phenotypic variability in ALS resistance $\left(\mathrm{R}^{2}=0.40-0.85\right.$, Supplementary Table 4) compared to significant single SNP markers.

\section{Haplotype-Specific SNPs to Advance Resistance Breeding by Marker-Assisted Selection}

Seven haplotype groups (M1-3, M5, A1-A3) were identified as potentially interesting for breeding because of the resistance they displayed in multiple experiments. For example, the SNP marker specific for M1, the haplotype group associated with strongest resistance against most pathotypes, offers unique opportunities to trace this effective resistance allele in advanced breeding germplasm (Figure 5A). Similarly, the SNP markers tagging M2 (Figure 5B) and M3 (Supplementary Table 5) can be employed for breeding to provide resistance against UG 61-63 (and the region of its occurrence). The SNP markers specific for the Andean haplotype groups A1 and A2 can be used to improve ALS resistance in the Andean gene pool, although their effectiveness is limited to a few pathotypes only. Genomic positions of the SNPs specific for all but one of the seven haplotype groups as well as for the resistance locus on Chr 4 are provided in Supplementary Table 5.

\section{DISCUSSION}

This study is the first to thoroughly evaluate the pathotypespecific response of ALS in common bean on the genetic level. Through GWAS in the largest yet assembled diversity panel segregating for ALS resistance, a pathotype-specific resistance locus, likely $P h g-4$, and a broad-spectrum resistance locus coinciding with Phg-2 were effective against a variety of ALS pathotypes from Colombia and Uganda. For the latter locus, a high haplotype diversity was found, with at least seven different haplotype groups providing resistance in a pathotype-specific manner. Molecular markers specific for resistance loci and haplotype groups will facilitate breeding for pathotype-specific ALS resistance through marker-assisted introgression strategies.

\section{No Effect of Phg-1, Phg-3, and Phg-5 Against the ALS Pathotypes Tested}

In common bean, ALS resistance is reportedly controlled by five major resistance loci, named Phg-1 to Phg-5 (Souza et al., 2016). Our study revealed a preeminent role of $P h g-2$, representing the unmatched source of resistance in effectively all experiments, while Phg-1, Phg-3, and Phg-5 did not appear to be relevant. This is unexpected as the resistance loci Phg-1 and Phg-5, originating from the resistance sources AND 277, CAL 143, and G5686 that were extensively used as progenitors in the CIAT breeding program, were present in the extBALSIT panel at frequencies sufficiently high to be detected by GWAS. Our observation may be a consequence of the strong pathotypespecificity of $P$. griseola and the differences in pathotypes prevalent within regions, countries, and continents. Experiments that led to the discovery of Phg-1 and Phg-3 were conducted with ALS evaluation protocols comparable to ours using pathotypes of the races 63-23 and 63-39 from Brazil (Gonçalves-Vidigal et al., 2011; Gonçalves-Vidigal et al., 2013). Phg-5 was discovered in CAL143 using a pathotype of race 0-39 and natural field evaluations in Brazil, and in G5686 using a pathotype of race 31-0 from Colombia (Oblessuc et al., 2012; Oblessuc et al., 2013; Keller et al., 2015). Brazilian pathotypes are known to be very aggressive on the current differentials (Balbi et al., 2009; Nietsche et al., 2001; Sartorato and Alzate-Marin, 2004; Silva et al., 2008), and it is possible that specific resistance genes are effective against these pathotypes. Future experiments should involve resistance evaluations of the extBALSIT panel with additional

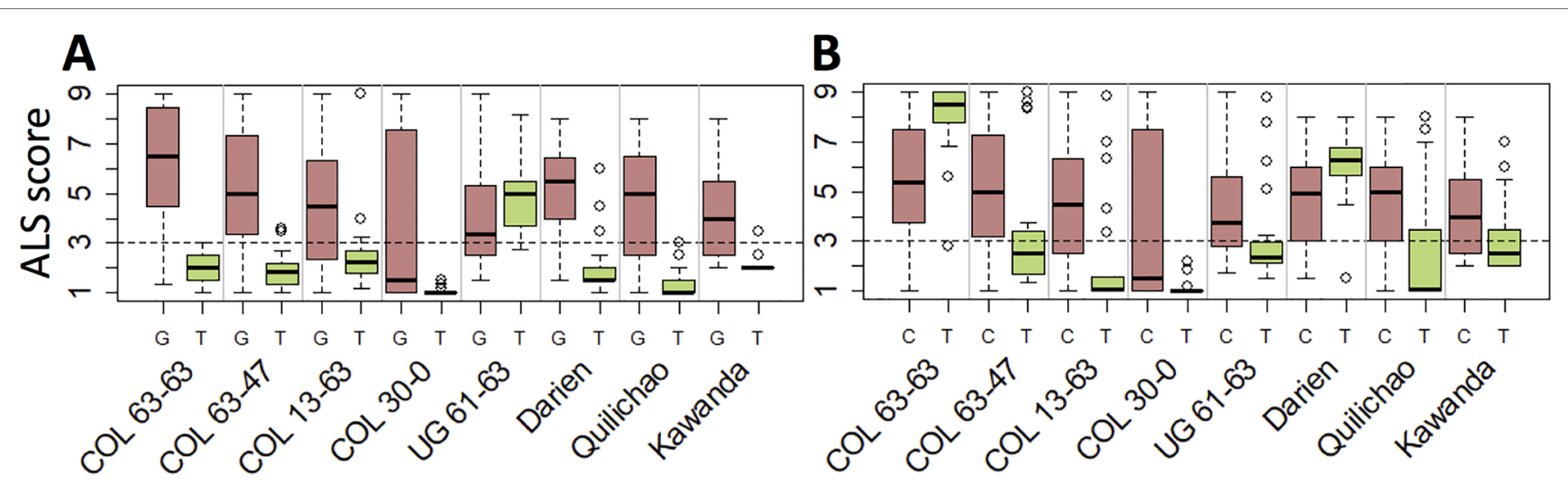

FIGURE 5 | Candidate SNPs for marker-assisted selection of Phg-2 haplotypes. Shown is the phenotypic distribution of ALS scores of the two alleles at the SNPs, which are specific for the functional haplotypes M1 (A) and M2 (B). The SNPs on chromosome 8 at position 61,901,182 bp and 62,188,623 bp of the Pv2.1 reference genome that co-segregated with the haplotype groups M1 and M2, respectively, were used. On the y-axis, ALS response scored on a scale from 1 to 9 is shown, whereas scores below 3 (dashed line) are considered resistant. On the x-axis, greenhouse and field trials are indicated, and for each trial, the ALS-resistance response of the two alleles of the SNP is plotted. 
pathotypes, particularly from Brazil, where the resistance loci Phg-1, Phg-3, and Phg-5 were observed to be effective.

In a similar study on resistance to anthracnose in common bean, an Andean bean diversity panel was tested with eight different pathotypes. In contrast to our study that only revealed a small subset of previously reported ALS resistance loci, GWAS for anthracnose resistance found the majority of the known resistance loci to effectively be involved (Zuiderveen et al., 2016). Our findings undermine the importance of the pathotypes on the efficacy of disease resistance in common bean and call for an increased understanding of the pathogen population structure and virulence to allow prediction of effectiveness of resistance loci. Once the population structure of the pathogen is better known, established GWAS panels can be used to study the pathotype-specificity within and between sub-populations.

\section{Phg-2 Is an Important ALS Resistance Locus With Functional Haplotypes From the Mesoamerican and the Andean Background}

The Phg-2 locus is one of the most important ALS resistance locus in common bean and originally described in the Mesoamerican cultivar Mexico 54 (Sartorato et al., 1999; Sartorato et al., 2000). In the meantime, several additional Mesoamerican common bean lines were found to contain ALS resistance, either at or in close proximity to $\mathrm{Phg}$-2 on Chr 8 (Nietsche et al., 2000; Mahuku et al., 2004; Namayanja et al., 2006; Mahuku et al., 2011). This led to the hypothesis that $P h g-2$ originated from the Mesoamerican gene pool, and hence, several breeding efforts aimed at its introgression into the Andean gene pool. Our study revealed that ALS resistance at Phg-2 can also be found in the Andean gene pool: through cluster analysis on the basis of the genotypic data in the $P h g-2$ region, we were able to classify eleven haplotype groups, at least seven of which appeared to be functionally different, leading to distinct patterns of resistance against the tested ALS pathotypes. Not only were resistance- and susceptibility- associated haplotypes in both gene pools, but also within each gene pool different haplotype groups of this resistance locus provided resistance to some, but not all evaluated ALS pathotypes.

\section{Genetic Determination of Pathotype- Specificity at Phg-2 on Chromosome 8}

The different haplotype groups at $P h g$ - 2 largely explained pathotypespecificity for ALS response. For further understanding of the detailed interaction on the molecular level, the underlying genetic determinants need to be identified. To date, the causal genes of any ALS resistance loci, including Phg-2, are yet to be determined. Based on our data, it remains difficult to resolve whether the resistance at $P h g-2$ is conferred by an allelic series at one resistance gene or by several resistance genes arrayed in clusters within the haplotype region defined by the significantly associated SNP markers.

Both, resistance gene clusters and allelic series are commonly occurring in plants (Keller et al., 2000). In common bean, several allelic series have been reported for anthracnose resistance, and there were five alleles described of the $\mathrm{Co}-1$ and $\mathrm{Co}-3$ loci, three alleles for the Co-4 locus, and two alleles for the Co-5 locus (BIC Genetics Committee, 2017). In wheat, up to 17 alleles have been found for the powdery mildew resistance gene Pm3 that showed different pathotype-specific reactions (Bhullar et al., 2010). The $P m 3$ gene encoded for a classical nucleotide binding leucine-rich repeat (NR-LRR) receptor and alleles were highly similar, with usually only single amino acid changes differing between the alleles (Yahiaoui et al., 2009). This pattern is reflecting the evolutionary mechanisms that are promoting the genetic diversification of resistance loci (Ellis et al., 2000; Bergelson et al., 2001).

Although the presence of allelic series may be a plausible explanation for ALS pathotype-specificity, the large extension of the Phg-2 region, spanning $1.78 \mathrm{Mbp}$ including 265 annotated genes, as well as the pathotype-specific significance peaks at distinct positions within this interval, indicates the involvement of multiple genes. Indeed, the presence of several candidate NB-LRR resistance genes at Phg-2 in the Andean reference genome and their distinct expression in leaf tissue, as the case with Phvul.008G284500 and Phvul.008G285300 (Phytozome, 2018), strengthens this hypothesis.

While these are probable candidate genes, it should be noted that the most effective haplotype groups at $\mathrm{Phg}-2$ originated from the Mesoamerican gene pool, while the reference genome used for SNP discovery and gene identification derived from the Andean gene pool (Schmutz et al., 2014). Resistance gene clusters are repetitive arrays of highly similar gene sequences that are often difficult to correctly assemble (Belser et al., 2018). Moreover, they usually differ in the number of repeats between common bean lines and gene pools, and hence, one reference genome might not be fully representative of the structural diversity at resistance loci. In the recent years, novel genome assembly strategies including long-read sequencing technologies have been developed to assemble such regions more accurately. With the increased availability of pan-genomes, it will be possible to take into account even the genetic rearrangements between common bean lines.

\section{Implications for ALS Resistance Breeding}

ALS is one of the most devastating common bean diseases, particularly affecting smallholder farmers in low input agricultural systems. The results are production losses to the poorest, which most depend on the harvest from their fields for food security. Breeding for ALS resistance and other biotic and abiotic stress has been ongoing for a long time in common bean breeding programs of the tropics (Beebe, 2012), but in the future, breeding needs to respond quicker than in the past to assure food security and adequate nutrition. Globalization and the increased human mobility have led to a globalization of plant pathogens and will continue to facilitate the exchange of genetic pathogen diversity (Anderson et al., 2004; Jeger et al., 2011; Fisher et al., 2012; Santini et al., 2018). An additional process that is expected to heavily affect plant pathogen dynamics is climate change. The increased warming and occurrence of extreme weather events will have effects on prevalence and plant-pathogen interactions (Anderson et al., 2004; Elad and Pertot, 2014). In the case of the tropical pathogen ALS, global warming will likely expand its range, and global mobility will lead to a mixing of pathogen populations previously separated by distance. More effective breeding methods are therefore urgently required to develop the varieties that will feed the growing future 
populations in developing countries. The research presented here will increase breeding efficiency for ALS resistance by providing a screening panel that can be used to find effective resistance loci in different areas. The molecular markers linked to resistance loci and resistance haplotypes will allow development of resistant lines without direct phenotypic screening in the region.

Resistance gene pyramiding is usually the suggested strategy to ensure durable disease resistance for highly virulent pathogens such as P. griseola (Pastor-Corrales et al., 1998). The fact that ALS resistance in nearly all trials was conferred by the different haplotypes at Phg-2 is rendering pyramiding difficult or impossible, depending on whether the causal genes are different genes within a resistance gene cluster or allelic series, respectively. Until the causal genes are known, the haplotype groups with very high effectiveness on both continents, M1 for Colombia and M2 and M3 for Uganda, provide the most sustainable strategy to control ALS by markerassisted selection in one of the globally most important food security crop. However, given the threat of resistance sources to become inefficient, it is crucial to seek new ALS resistant common bean lines and elucidate the genetics of their resistance (Nay et al., 2019).

\section{DATA AVAILABILITY}

The datasets analyzed and generated for this study can be found on dataverse at https://doi.org/10.7910/DVN/U2BAWN.

\section{AUTHOR CONTRIBUTIONS}

$\mathrm{BR}$ and BS conceived the study. MN conducted the experiments and performed data analysis and interpretation. BR, BS, and CM assisted in the experimental setup and data analysis. MN drafted

\section{REFERENCES}

Anderson, P. K., Cunningham, A. A., Patel, N. G., Morales, F. J., Epstein, P. R., and Daszak, P. (2004). Emerging infectious diseases of plants: pathogen pollution, climate change and agrotechnology drivers. Trends Ecol. Evol. 19 (10), 535-544. doi: 10.1016/j.tree.2004.07.021

Balbi, B. P., Sanglard, D. A., Arruda, K. M. A., Costa, M. R., Piovesan, N. D., de Barros, E. G., et al. (2009). Characterization of Pseudocercospora griseola isolates collected in the state of Minas Gerais, Brazil. Annu. Rep. Bean Improv. Coop. 52, 56-57.

Bassi, D., Briñez, B., Rosa, J. S., Oblessuc, P. R., Almeida, C. P., De Nucci, S. M., et al. (2017). Linkage and mapping of quantitative trait loci associated with angular leaf spot and powdery mildew resistance in common beans. Genet. Mol. Biol. 40 (1), 109-122. doi: 10.1590/1678-4685-gmb-2015-0314

Beebe, S. E. (2012). "Common bean breeding in the tropics," in Plant Breeding Reviews, vol. 36. Ed. J. Janick (Hoboken NJ, USA: Wiley-Blackwell), 357-426. doi: 10.1002/9781118358566.ch5

Beebe, S. E., Tohme, P., Duque, J., Pedraza, M., Nienhuis, F. (2000). Structure of genetic diversity among common bean landraces of Middle American origin based on correspondence analysis of RAPD. Crop Sci. 40, 264-273. doi: 10.2135/cropsci2000.401264x

Belser, C., Istace, B., Denis, E., Dubarry, M., Baurens, F. C., Falentin, C., et al. (2018). Chromosome-scale assemblies of plant genomes using nanopore long reads and optical maps. Nat. Plants 4, 879-887. doi: 10.1038/s41477-018-0289-4

Bergelson, J., Kreitman, M., Stahl, E. A., and Tian, D. (2001). Evolutionary dynamics of plant R-genes. Science 292 (5525), 2281-2285. doi: 10.1126/ science. 1061337 the manuscript, which was improved by BS, BR, and CM. All authors read and approved the final manuscript.

\section{FUNDING}

This project was funded by ETH Global, the Sawiris Foundation for Social Development and supported by the Molecular Plant Breeding group of ETH Zurich. We would also like to acknowledge funding support from the Tropical Legumes III - Improving Livelihoods for Smallholder Farmers: Enhanced Grain Legume Productivity and Production in Sub-Saharan Africa and South Asia (OPP1114827) project funded by the Bill \& Melinda Gates Foundation.

\section{ACKNOWLEDGMENTS}

We would like to acknowledge the help of H. F. Buendia, A. E. Portilla and V. M. Mayor for technical assistance during field trials and seed handling, D. Ariza and S. Yates for help with bioinformatics analyses and E. Macea and L. M. Diaz for lab assistance. Furthermore, we would like to acknowledge CIAT pathology unit for assistance with pathogen handling. In addition, we would like to thank the staff at CIAT Uganda, specifically F. Kato, S. Musoke, S. Sulaiman and C. Acam for help in conducting field and greenhouse trials.

\section{SUPPLEMENTARY MATERIAL}

The Supplementary Material for this article can be found online at: https://www.frontiersin.org/articles/10.3389/fpls.2019.01126/ full\#supplementary-material

Bhullar, N. K., Zhang, Z., Wicker, T., and Keller, B. (2010). Wheat gene bank accessions as a source of new alleles of the powdery mildew resistance gene Pm3: a large scale allele mining project. BMC Plant Biol. 10, 1-13. doi: 10.1186/1471-2229-10-88

BIC (Bean Improvement Cooperative) Genetics Committee. (2017). List of genesPhaseolus vulgaris L. Retrieved October 24, 2018, from http://arsftfbean.uprm. edu/bic/wp-content/uploads/2018/04/Bean_Genes_List_2017.pdf

Bradbury, P. J., Zhang, Z., Kroon, D. E., Casstevens, T. M., Ramdoss, Y., and Buckler, E. S. (2007). TASSEL: software for association mapping of complex traits in diverse samples. Bioinformatics 23 (19), 2633-2635. doi: 10.1093/ bioinformatics/btm 308

Busogoro, J. P., Jijakli, M. H., and Lepoivre, P. (1999). Virulence variation and RAPD polymorphism in African isolates of Phaeoisariospis griseola (Sacc.) Ferr., the causal agent of angular leaf spot of common bean. Eur. J. Plant Pathol. 105 (6), 559-569. doi: 10.1023/A:1008707101645

Caixeta, E. T., Borém, A., De Azevedo Fagundes, S., Niestche, S., De Barros, E. G., and Moreira, M. A. (2003). Inheritance of angular leaf spot resistance in common bean line BAT 332 and identification of RAPD markers linked to the resistance gene. Euphytica 134 (3), 297-303. doi: 10.1023/B:EUPH.0000004948.41083.1f

Carvalho, G. A., Paula Junior, T. J., Alzate-Marin, A. L., Nietsche, S., Barros, E. G., and Moreira, M. A. (1998). Inheritance of resistance of the Andean bean line AND-277 to race 63-23 of Phaeoisariopsis griseola and identification of a RAPD marker linked to the resistance gene. Fitopatol. Bras. 23 (4), 482-485.

Castellanos, G., Jara, C., and Mosquera, G. (2016). Bean pathogens: practical guide for lab and greenhouse work. 2nd ed. Cali, Colombia: CIAT. 
Chen, J., Greenblattt, I. M., and Dellaporta, S. L. (1992). Molecular analysis of Ac transposition and DNA replication. Genetics 130, 665-676.

CIAT Genebank. (2018). Bean collection. Retrieved October 24, 2018, from http:// genebank.ciat.cgiar.org/genebank/beancollection.do

Correa-Victoria, F. J., Pastor-Corrales, M. A., and Saettler, A. W. (1989). "Angular leaf spot," in Bean Production Problems in the Tropics. Eds. H. F. Schwartz and M. A. Pastor-Corrales (Cali, Colombia: CIAT), 59-75.

Corrêa, R. X., Good-God, P. I. V., Oliveira, M. L. P., Nietsche, S., Moreira, M. A., and Barros, E. G. D. E. (2001). Herança da resistência à mancha-angular do feijoeiro e identificação de marcadores moleculares flanqueando o loco de resistência. Fitopatol. Bras. 26 (1), 27-32. doi: 10.1590/S0100-41582001000100005

Crous, P. W., Liebenberg, M. M., Braun, U., and Groenewald, J. Z. (2006). Re-evaluating the taxonomic status of Phaeoisariopsis griseola, the causal agent of angular leaf spot of bean. Stud. Mycol. 55 (1995), 163-173. doi: 10.3114/ sim.55.1.163

Ddamulira, G., Mukankusi, C., Ochwo-Ssemakula, M., Edema, R., Sseruwagi, P., and Gepts, P. (2014). Distribution and variability of Pseudocercospora griseola in Uganda. J. Agric. Sci. 6 (6), 16-29. doi: 10.5539/jas.v6n6p16

Elad, Y., and Pertot, I. (2014). Climate change impacts on plant pathogens and plant diseases. J. Crop Improv. 28 (1), 99-139. doi: 10.1080/15427528.2014.865412

Ellis, J., Dodds, P., and Pryor, T. (2000). Structure, function and evolution of plant disease resistance genes. Curr. Opin. Plant Biol. 3, 278-284. doi: 10.1016/ S1369-5266(00)00080-7

Elshire, R. J., Glaubitz, J. C., Sun, Q., Poland, J. A., Kawamoto, K., Buckler, E. S., et al. (2011). A robust, simple genotyping-by-sequencing (GBS) approach for high diversity species. PLoS One 6 (5), 1-10. doi: 10.1371/journal.pone.0019379

Endelman, J. B., and Jannink, J.-L. (2012). Shrinkage estimation of the realized relationship matrix. G3-Genes Genomes Genet. 2 (11), 1405-1413. doi: 10.1534/ g3.112.004259

Ferreira, C. F. F., Borém, A., Carvalho, G. A. A., Nietsche, S., Paula, T. J. J., Barros, E. G. G., et al. (2000). Inheritance of angular leaf spot resistance in common bean and identification of a rapd marker linked to a resistance gene. Crop Sci. 40 (4), 1130-1133. doi: 10.2135/cropsci2000.4041130x

Fisher, M. C., Henk, D. A., Briggs, C. J., Brownstein, J. S., Madoff, L. C., McCraw, S. L., et al. (2012). Emerging fungal threats to animal, plant and ecosystem health. Nature 484 (7393), 186-194. doi: 10.1038/nature10947

Gepts, P., and Debouck, D. (1991). "Origin, domestication, and evolution of the common bean (Phaseolus vulgaris L.)," in Common beans: research for crop improvement (Wallingford, UK: CABI), 7-53.

Gil, J., Jara, C. E., Lobaton, J. D., and Raatz, B. (2019). Fine mapping of angular leaf spot resistance gene Phg-2 in common bean and development of breeding markers. Theor. Appl. Genet. 132, 2003-2016. doi: 10.1007/ s00122-019-03334-z

Gonçalves-Vidigal, M. C., Cruz, A. S., Garcia, A., Kami, J., Filho, P. S. V., Sousa, L. L., et al. (2011). Linkage mapping of the Phg-1 and Co-14 genes for resistance to angular leaf spot and anthracnose in the common bean cultivar AND 277. Theor. Appl. Genet. 122 (5), 893-903. doi: 10.1007/s00122-010-1496-1

Gonçalves-Vidigal, M. C., Cruz, A. S., Lacanallo, G. F., Vidigal Filho, P. S., Sousa, L. L., Pacheco, C. M. N. a, et al. (2013). Co-segregation analysis and mapping of the anthracnose $\mathrm{Co}-10$ and angular leaf spot Phg-ON diseaseresistance genes in the common bean cultivar Ouro Negro. Theor. Appl. Genet. 126 (9), 2245-2255. doi: 10.1007/s00122-013-2131-8

Guzmán, P., Gilbertson, R. L., Nodari, R. O., Johnson, W. C., Temple, S. R., Mandala, D., et al. (1995). Characterization of variability in the fungus Phaeoisariopsis griseola suggests coevolution with the common bean (Phaseolus vulgaris). Phytopathology 85 (5), 600-607. doi: 10.1094/Phyto-85-600

Holland, J. B. (2004). "Implementation of molecular markers for quantitative traits in breeding programs-challenges and opportunities," In New directions for a diverse planet: Proceedings of the 4th International Crop Science Congress (Gosford, Australia: The Regional Institue Ltd).

Jeger, M., Pautasso, M., and Stack, J. (2011). "Climate, globalization, and trade: impacts on dispersal and invasion of fungal plant pathogens," in Fungal diseases: an emerging threat to human, animal and plant health. Eds. L. Olsen, E. R. Choffnes, and D. A. Relman (Washington DC, USA: The National Academies Press), 273-296.

Keller, B., Feuillet, C., and Messmer, M. (2000). "Genetics of disease resistancebasic concepts and its application in resistance breeding," in Mechanisms of Resistance to Plant Diseases. Eds. A. Slusarenko, R. Fraser, and K. van Loon
(Dordrecht, Netherlands: Kluwer Academic Publishers), 101-160. doi: 10.1007/978-94-011-3937-3_5

Keller, B., Manzanares, C., Jara, C., Lobaton, J. D., Studer, B., and Raatz, B. (2015). Fine-mapping of a major QTL controlling angular leaf spot resistance in common bean (Phaseolus vulgaris L.). Theor. Appl. Genet. 128 (5), 813-826. doi: 10.1007/s00122-015-2472-6

Kumar, A., Dixit, S., Ram, T., Yadaw, R. B., Mishra, K. K., and Mandal, N. P. (2014). Breeding high-yielding drought-tolerant rice: genetic variations and conventional and molecular approaches. J. Exp. Bot. 65 (21), 6265-6278. doi: $10.1093 / \mathrm{jxb} / \mathrm{eru} 363$

Lobaton, J. D., Miller, T., Gil, J., Ariza, D., de la Hoz, J. F., Soler, A., et al. (2018). Re-sequencing of common bean identifies regions of inter-gene pool introgression and provides comprehensive resources for molecular breeding. Plant Genome 11 (2), 1-21. doi: 10.3835/plantgenome2017.08.0068

Mahuku, G. S., Henríquez, M. A., Montoya, C., Jara, C., Teran, H., Beebe, S. E., et al. (2011). Inheritance and development of molecular markers linked to angular leaf spot resistance genes in the common bean accession G10909. Mol. Breed. 28 (1), 57-71. doi: 10.1007/s11032-010-9461-x

Mahuku, G. S., Henríquez, M. A., Munõz, J., and Buruchara, R. (2002a). Molecular markers dispute the existence of the Afro-Andean group of the bean angular leaf spot pathogen, Phaeoisariopsis griseola. Phytopathology 92 (6), 580-589. doi: 10.1094/PHYTO.2002.92.6.580

Mahuku, G. S., Iglesias, A. M., and Jara, C. (2009). Genetics of angular leaf spot resistance in the Andean common bean accession G5686 and identification of markers linked to the resistance genes. Euphytica 167 (3), 381-396. doi: 10.1007/s10681-009-9897-4

Mahuku, G. S., Jara, C., Cajiao, C., and Beebe, S. (2003). Sources of resistance to angular leaf spot (Phaeoisariopsis griseola) in common bean core collection, wild Phaseolus vulgaris and secondary gene pool. Euphytica 130 (3), 303-313. doi: 10.1023/A:1023095531683

Mahuku, G. S., Jara, C., Cuasquer, J. B., and Castellanos, G. (2002b). Genetic variability within Phaeoisariopsis griseola from Central America and its implications for resistance breeding of common bean. Plant Pathol. 51 (5), 594-604. doi: 10.1046/j.1365-3059.2002.00742.x

Mahuku, G., Montoya, C., Henríquez, M. A., Jara, C., Teran, H., and Beebe, S. (2004). Inheritance and characterization of angular leaf spot resistance gene present in common bean accession G 10474 and identification of an AFLP marker linked to the resistance gene. Crop Sci. 44 (5), 1817-1824. doi: 10.2135/ cropsci2004.1817

Mamidi, S., Rossi, M., Moghaddam, S. M., Annam, D., Lee, R., Papa, R., et al. (2013). Demographic factors shaped diversity in the two gene pools of wild common bean Phaseolus vulgaris L. Heredity 110 (3), 267-276. doi: 10.1038/ hdy.2012.82

Murtagh, F., and Legendre, P. (2014). Ward's hierarchical agglomerative clustering method: which algorithms implement Ward's criterion? J. Classif. 31, 274-295. doi: 10.1007/s00357-014-9161-z

Namayanja, A., Buruchara, R., Mahuku, G., Rubaihayo, P., Kimani, P., Mayanja, S., et al. (2006). Inheritance of resistance to angular leaf spot in common bean and validation of the utility of resistance linked markers for marker assisted selection outside the mapping population. Euphytica 151 (3), 361-369. doi: 10.1007/s10681-006-9158-8

Nay, M. M., Souza, T. L. P. O., Gonçalves-Vidigal, M. C., Raatz, B., Mukankusi, C. M., Abreu, Â. F. B., et al. (2019). A review of angular leaf spot resistance in common bean. Crop Sci. 59, 1376-1391. doi: 10.2135/cropsci2018.09.0596

Nietsche, S., Borém, A., Assis De Carvalhos, G., De Paula Júnor, T. J., Fortes Ferreira, C., Gonçalves De Barros, E., et al. (2001). Genetic diversity of Phaeoisariopsis griseola in the State of Minas Gerais, Brazil. Euphytica 117 (1), 77-84. doi: 10.1023/A:1004096421990

Nietsche, S., Borém, A., Carvalho, G. A., Rocha, R. C., Paula, T. J., De Barros, E. G., et al. (2000). RAPD and SCAR markers linked to a gene conferring resistance to angular leaf spot in common bean. J. Phytopathol. 148 (2), 117-121. doi: 10.1046/j.1439-0434.2000.00479.x

Oblessuc, P. R., Baroni, R. M., Garcia, A. A. F., Chioratto, A. F., Carbonell, S. A. M., Camargo, L. E. A., et al. (2012). Mapping of angular leaf spot resistance QTL in common bean (Phaseolus vulgaris L.) under different environments. BMC Genet. 13 (50), 1-9. doi: 10.1186/1471-2156-13-50

Oblessuc, P. R., Cardoso Perseguini, J. M. K., Baroni, R. M., Chiorato, A. F., Carbonell, S. A. M., Mondego, J. M. C., et al. (2013). Increasing the density of markers 
around a major QTL controlling resistance to angular leaf spot in common bean. Theor. Appl. Genet. 126 (10), 1-15. doi: 10.1007/s00122-013-2146-1

Oerke, E. C. (2006). Crop losses to pests. J. Agric. Sci. 114, 31-43. doi: 10.1017/ S0021859605005708

Pastor-Corrales, M. A., and Jara, C. E. (1995). The evolution of Phaeoisariopsis griseola with the common bean in Latin America. Fitopatol. Colomb. 1 (19), 15-24.

Pastor-Corrales, M. A., Jara, C., and Singh, S. P. (1998). Pathogenic variation in 'sources of' and breeding for resistance to Phaeoisariopsis griseola causing angular leaf spot in common bean. Euphytica 103 (2), 161-171. doi: 10.1023/A:1018350826591

Perea, C., De La Hoz, J. F., Cruz, D. F., Lobaton, J. D., Izquierdo, P., and Quintero, J. C. (2016). Bioinformatic analysis of genotype by sequencing (GBS) data with NGSEP. BMC Genomics 175, 539-551. doi: 10.1186/s12864-016-2827-7

Phytozome. (2018). Phaseolus vulgaris v2.1 (Common bean). Department of Energy-Joint Genome Institute (DOE-JGI) and United States Agriculture Department National Institute of Food and Agriculture (USDA-NIFA). Retrieved November 11, 2018 from https://phytozome.jgi.doe.gov/pz/portal. html\#! info?alias=Org_Pvulgaris

R Core Team. (2008). R: a language and environment for statistical computing. Vienna, Austria: R Foundation for Statistical Computing.

Saettler, A. W. (1991). "Angular leaf spot," in Compendium of bean diseases. Ed. R. Hall (St. Paul MN, USA: The American Phytopathological Society Press (APS)).

Santini, A., Liebhold, A., Migliorini, D., and Woodward, S. (2018). Tracing the role of human civilization in the globalization of plant pathogens. ISME J. 12 (3), 647-652. doi: 10.1038/s41396-017-0013-9

Sartorato, A. (2004). Pathogenic variability and genetic diversity of Phaeoisariopsis griseola isolates from two counties in the state of Goias, Brazil. J. Phytopathol. 152 (7), 385-390. doi: 10.1111/j.1439-0434.2004.00858.x

Sartorato, A., and Alzate-Marin, A. L. (2004). Analysis of the pathogenic variability of Phaeoisariopsis griseola in Brazil. Annu. Rep. Bean Improv. Coop. 47, 235-236.

Sartorato, A., Nietsche, S., Barros, E. G., and Moreira, M. A. (1999). SCAR marker linked to angular leaf spot resistance gene in common bean. Annu. Rep. Bean Improv. Coop. 47, 23-24.

Sartorato, A., Nietsche, S., Barros, E., and Moreira, M. A. (2000). RAPD and SCAR markers linked to resistance gene to angular leaf spot in common beans. Fitopatol. Bras. 25, 637-642.

Savary, S., Ficke, A., Aubertot, J. N., and Hollier, C. (2012). Crop losses due to diseases and their implications for global food production losses and food security. Food Sec. 4 (4), 519-537. doi: 10.1007/s12571-012-0200-5

Schmutz, J., McClean, P. E., Mamidi, S., Wu, G. A., Cannon, S. B., Grimwood, J., et al. (2014). A reference genome for common bean and genome-wide analysis of dual domestications. Nat. Genet. 46 (7), 707-713. doi: 10.1038/ng.3008

Schwartz, H. F., Correa, F., Pineda, P., Otoya, M. M., and Katherman, M. J. (1981). Dry bean yield losses caused by Ascochyta, angular, and white leaf spots in Colombia. Plant Dis. 65 (6), 494-496. doi: 10.1094/PD-65-494
Schwartz, H. F., and Pastor-Corrales, M. A. (1989). Bean production problems in the tropics. 2nd ed. Cali, Colombia: CIAT.

Silva, K. J. D., De Souza, E. A., Sartorato, A., and De Souza Freire, C. N. (2008). Pathogenic variability of isolates of Pseudocercospora griseola, the cause of common bean angular leaf spot, and its implications for resistance breeding. J. Phytopathol. 156 (10), 602-606. doi: 10.1111/j.1439-0434.2008.01413.x

Souza, T. L. P. O., Gonçalves-Vidiga, M. C., Raatz, B., Mukankusi, C. M., Abreu, Â. F. B., Melo, L. C., et al. (2016). Major loci controlling resistance to the angular leaf spot of common bean. Annu. Rep. Bean Improv. Coop. 59, 49-50.

Stenglein, S., Ploper, L. D., Vizgarra, O., and Balatti, P. (2003). Angular leaf spot: a disease caused by the fungus Phaeoisariopsis griseola (Sacc.) Ferraris on Phaseolus vulgaris L. Adv. App. Microbiol. 52, 209-243. doi: 10.1016/ S0065-2164(03)01009-8

Teixeira, F. F., Santos, J. B., Ramalho, M. A P., Abreu, Â. F. B., Guimarães, C. T., and Oliveria, A. C. (2005). QTL mapping for angular leaf spot in common bean using microsatellite markers. Crop Breed. Appl. Biotechnol. 5, 272-278. doi: 10.12702/1984-7033.v05n03a03

van Schoonhoven, A., and Pastor-Corrales, M. A. (1987). Standard system for the evaluation of bean germplasm. Cali, Colombia: CIAT.

Ward, J. H. (1963). Hierarchical grouping to optimize an objective function. J. Am. Stat. Assoc. 58 (301), 236-244. doi: 10.1080/01621459.1963.10500845

Wortmann, C. S., Kirkby, R. A., Eledu, C. A., and Allen, D. J. (1998). Atlas of common bean (Phaseolus vulgaris L.) production in Africa. Cali, Colombia: CIAT.

Yahiaoui, N., Kaur, N., and Keller, B. (2009). Independent evolution of functional $P m 3$ resistance genes in wild tetraploid wheat and domesticated bread wheat. Plant J. 57 (5), 846-856. doi: 10.1111/j.1365-313X.2008.03731.x

Zhang, Z., Ersoz, E., Lai, C., Todhunter, R. J., Tiwari, H. K., Gore, M. a, et al. (2010). Mixed linear model approach adapted for genome-wide association studies. Nat. Genet. 42 (4), 355-360. doi: 10.1038/ng.546

Zuiderveen, G. H., Padder, B. A., Kamfwa, K., Song, Q., and Kelly, J. D. (2016). Genome-wide association study of anthracnose resistance in Andean beans (Phaseolus vulgaris). PLoS One 11 (6), 1-17 doi: 10.1371/journal.pone.0156391.

Conflict of Interest Statement: The authors declare that the research was conducted in the absence of any commercial or financial relationships that could be construed as a potential conflict of interest.

Copyright (c) 2019 Nay, Mukankusi, Studer and Raatz. This is an open-access article distributed under the terms of the Creative Commons Attribution License (CC BY). The use, distribution or reproduction in other forums is permitted, provided the original author(s) and the copyright owner(s) are credited and that the original publication in this journal is cited, in accordance with accepted academic practice. No use, distribution or reproduction is permitted which does not comply with these terms. 